\title{
THE UNITY OF PAROXYSMAL TACHYCARDIA AND AURICULAR FLUTTER
}

\author{
BY \\ WILLIAM EVANS \\ From the Cardiac Department of the London Hospital \\ Received November 11, 1944
}

It is difficult in the common electrocardiogram of paroxysmal tachycardia to identify the auricular wave and to place it in relation to the ventricular complex. Accordingly the cardiographic classification for paroxysmal tachycardia based on the position of the $P$ wave (deformed and preceding the $R$ wave in the auricular type, succeeding or coinciding with the $R$ in the auriculo-ventricular or nodal variety, and normal in the ventricular type) has not always been easy to follow in practice. Again, the record has often resembled that customarily called auricular flutter. As a rule the rhythm is readily distinguished from sinus tachycardia. Fortunately the treatment of paroxysmal tachycardia has not suffered from failure to understand its exact mechanism, since attention has usually been directed to the underlying heart condition, and digitalis and quinidine have been given a trial for the correction of the arrhythmia. Nonetheless, the actual mechanism of the attack has engaged the diligent search of many investigators, and a contribution to this subject is worth while.

The clear portrayal of auricular movements in auricular fibrillation (Fig. 1) in the right pectoral $\left(\mathrm{CR}_{1}\right)$ cardiogram (Evans, 1941) led me to apply chest leads to patients with paroxysmal tachycardia at the time of the attack. This paper gives the result of such cardiographic examination in 27 consecutive cases. The diagnosis of paroxysmal tachycardia was made when each patient told of periods of palpitation, starting abruptly and usually ending as suddenly after lasting a variable time during which the heart rate was very rapid, and when the limb lead cardiogram showed a high frequency of the ventricular beat, absence of sinoauricular rhythm, and auricular waves removed from their customary place in relation to the ventricular waves if decipherable at all. It is inevitable, therefore, that some of the tracings recorded here might be regarded by some as instances of auricular flutter, although they conform to the definition given above.

During the early part of the investigation three chest leads were used, namely, the right pectoral $\left(\mathrm{CR}_{1}\right)$, apical (IVR), and the posterior axillary $\left(\mathrm{CR}_{7}\right)$. When it became evident that the auricular waves did not show to better advantage in $\mathrm{CR}_{\mathbf{7}}$ than in the limb leads, it was discontinued as a routine test. Sometimes the auricular movements were depicted clearly in IVR, but they were best in $\mathrm{CR}_{1}$ so this lead was taken in every patient.

\section{RESULTS OF THE INVESTIGATION}

The first tracings showed tachycardia with auricular beats twice as numerous as the ventricular, and when the $\mathrm{CR}_{1}$ cardiogram was examined for the complete series it showed $2: 1 \mathrm{~A}-\mathrm{V}$ dissociation in every patient, although the limb lead had not often indicated this fact. For the purpose of analysis the cases may be separated into three groups according to the auricular and ventricular rates and the relationship of the auricular waves to the QRS 


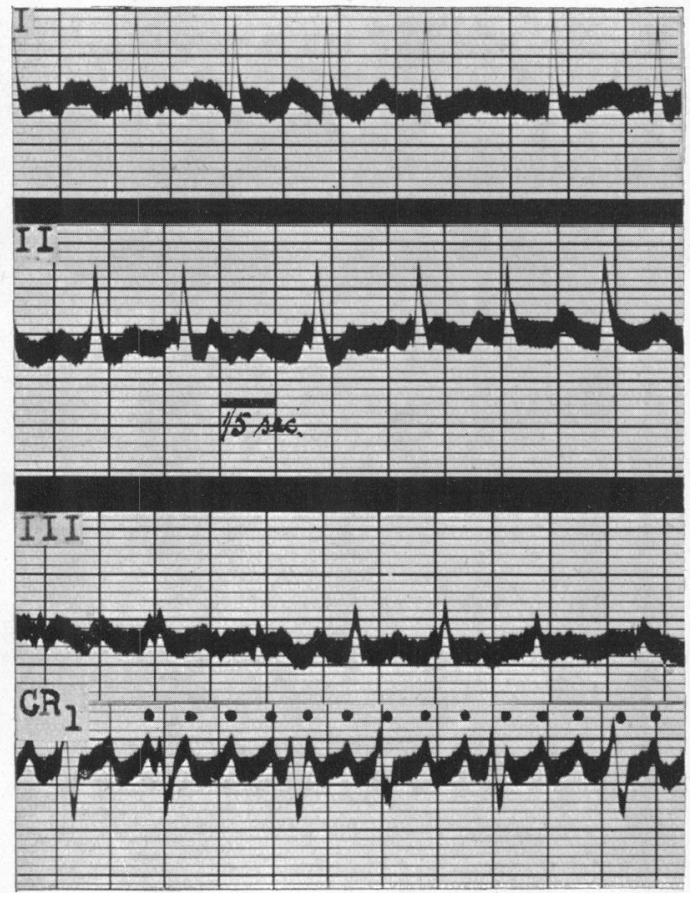

FIG. 1.-Auricular fibrillation; auricular rate (A.R.) 428, ventricular rate (V.R.) 150 . Auricular waves in $C_{1}$ show regular rhythm but slight irregularity in form. Male, aged 52, with cardiac infarction. In this and in other figures dots or arrows designate auricular beats.

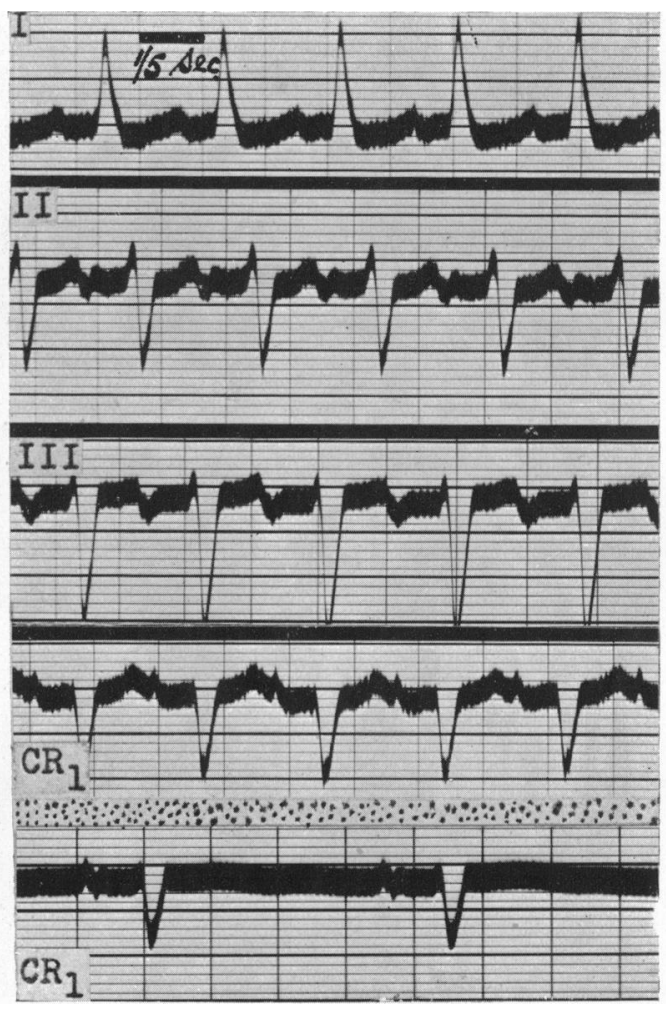

FIG. 2.-Sinus tachycardia resembling auricular tachycardia in limb leads. $\mathrm{CR}_{1}$ recorded when pulse was rapid and again at normal rate, confirmed sinus rhythm. Flat $T$ wave in second $C_{1}$ from digitalis effect. Healthy female, aged 44 , complaining of palpitation.

and $\mathrm{T}$ waves in the $\mathrm{CR}_{1}$ lead. In one group, the rate was slow enough to allow both auricular waves to be shown. In another, the rate was more rapid so that one auricular wave was visible and the alternate one obscured by the coincidence of either the $S$ or $T$ wave of the ventricular complex. In the third group the rate was so rapid as to include and hide both auricular waves in the $S$ and $T$ waves respectively. Naturally the identification of $A-V$ dissociation was not difficult in cases forming the first of these groups from reference to the limb lead cardiogram, but it was impossible in the other two groups. It is known that separation of the auricular and ventricular waves, by slowing the ventricular rate, cannot always be brought about by such measures as digitalization, quinidine therapy, and pressure on the carotid sinus, and in this series also such procedures commonly failed. It was possible, however, to identify the higher frequency of the auricular beats in the $\mathrm{CR}_{1}$ cardiogram of each of the 27 cases in spite of the handicap of moderately severe tachycardia at times; the identification of the auricular waves in the second and third groups was helped by comparing the right pectoral tracing with one taken during normal rhythm either before or after the paroxysm. The value of this plan is illustrated in cardiograms from a patient thought to have paroxysmal tachycardia; during a spell of palpitation the rapid auricular waves were seen in $\mathrm{CR}_{1}$ tracing (Fig. 2) to have the same rate as the ventricular waves. If an extra auricular wave had been present in this case it would have coincided with the $S$ wave and produced an $R^{1}$ wave in $C_{1}$ during the attack. Since the $S$ wave has the same pattern during tachycardia and when the rate was normal, the rapid heart action arose from the sino-auricular node. 
TABLE I

The Right Pectoral Electrocardiogram $\left(\mathrm{CR}_{1}\right)$ in 27 Consecutive Cases of Paroxysmal Tachycardia, and in 7 Casual Examples of Established Auricular Flutter

\begin{tabular}{|c|c|c|c|c|c|c|c|c|}
\hline \multirow{2}{*}{$\begin{array}{c}\text { Initials } \\
\text { or } \\
\text { Case } \\
\text { No. }\end{array}$} & \multirow{2}{*}{ Age } & \multirow{2}{*}{$\begin{array}{c}\text { Nature of } \\
\text { underlying heart } \\
\text { disease }\end{array}$} & \multicolumn{2}{|c|}{ Auricular rate } & \multicolumn{2}{|c|}{ Ventricular rate } & \multirow{2}{*}{$\begin{array}{l}\text { Distinctive features } \\
\text { of the right } \\
\text { pectoral } \\
\text { electrocardiogram }\end{array}$} & \multirow{2}{*}{$\begin{array}{l}\text { Particular } \\
\text { ventricular } \\
\text { wave } \\
\text { obscuring } \\
\text { auricular } \\
\text { wave }\end{array}$} \\
\hline & & & $\begin{array}{l}\text { Indi- } \\
\text { vidual }\end{array}$ & Group $\dagger$ & $\begin{array}{l}\text { Indi- } \\
\text { vidual }\end{array}$ & Group & & \\
\hline $\begin{array}{l}\text { F. A. } \\
\text { E. C. } \\
\text { E. D. } \\
\text { A. E. } \\
\text { P. B. } \\
\text { F. S. } \\
\text { H. D. }\end{array}$ & $\begin{array}{l}61 \\
62 \\
62 \\
43 \\
70 \\
57 \\
50\end{array}$ & $\begin{array}{l}\text { Hypertension } \\
\text { Hypertension } \\
\text { Healthy } \\
\text { Mitral stenosis } \\
\text { Healthy } \\
\text { Hypertension } \\
\text { Mitral stenosis }\end{array}$ & $\begin{array}{l}280 \\
280 \\
230 \\
328 \\
292 \\
300 \\
236\end{array}$ & Variable & $\begin{array}{l}23 \\
34 \\
40 \\
50 \\
73 \\
75 \\
80\end{array}$ & $\begin{array}{c}\text { Under } \\
100\end{array}$ & $\begin{array}{l}3: 1 \text { (or greater) } \\
\text { A-V dissociation. } \\
\text { Three or more con- } \\
\text { secutive auricular } \\
\text { waves outside } \\
\text { ventricular waves }\end{array}$ & $\begin{array}{l}- \\
- \\
- \\
-\end{array}$ \\
\hline $\begin{array}{l}1 \\
2 \\
3 \\
4^{*} \\
5^{*}\end{array}$ & $\begin{array}{l}46 \\
60 \\
21 \\
69 \\
28\end{array}$ & $\begin{array}{l}\text { Mitral stenosis } \\
\text { Mitral stenosis } \\
\text { Healthy } \\
\text { Hypertension } \\
\text { Mitral stenosis }\end{array}$ & $\begin{array}{l}210 \\
212 \\
240 \\
254 \\
256\end{array}$ & $\begin{array}{c}200 \\
\text { to } \\
260\end{array}$ & $\begin{array}{l}105 \\
106 \\
120 \\
127 \\
128\end{array}$ & $\begin{array}{c}100 \\
\text { to } \\
130\end{array}$ & $\begin{array}{l}2: 1 \text { A-V dissocia- } \\
\text { tion. Both auricular } \\
\text { waves outside } \\
\text { ventricular waves }\end{array}$ & $\begin{array}{l}- \\
- \\
-\end{array}$ \\
\hline $\begin{array}{l}6 \\
7 * \\
8 \\
9 \\
10 \\
11 \\
12 \\
13 \\
14 \\
15^{*} \\
16^{*} \\
17 \\
18 \\
19^{*} \\
20\end{array}$ & $\begin{array}{l}68 \\
58 \\
65 \\
53 \\
52 \\
63 \\
58 \\
38 \\
34 \\
61 \\
50 \\
64 \\
53 \\
59 \\
19\end{array}$ & $\begin{array}{l}\text { Hypertension } \\
\text { Mitral stenosis } \\
\text { Mitral stenosis } \\
\text { Mitral stenosis } \\
\text { Mitral stenosis } \\
\text { Hypertension } \\
\text { Mitral stenosis } \\
\text { Healthy } \\
\text { Healthy } \\
\text { Hypertension } \\
\text { Mitral stenosis } \\
\text { Healthy } \\
\text { Cardiac infarction } \\
\text { Cardiac infarction } \\
\text { Healthy }\end{array}$ & $\begin{array}{l}260 \\
264 \\
264 \\
282 \\
282 \\
292 \\
300 \\
308 \\
320 \\
332 \\
338 \\
342 \\
364 \\
376 \\
380\end{array}$ & $\begin{array}{c}260 \\
\text { to } \\
400\end{array}$ & $\begin{array}{l}130 \\
132 \\
132 \\
141 \\
141 \\
146 \\
150 \\
154 \\
160 \\
166 \\
169 \\
171 \\
182 \\
188 \\
190\end{array}$ & $\begin{array}{c}130 \\
\text { to } \\
200\end{array}$ & $\begin{array}{l}2: 1 \text { A-V dissocia- } \\
\text { tion. Alternate } \\
\text { auricular waves } \\
\text { within a } \\
\text { ventricular wave }\end{array}$ & $\begin{array}{l}S \\
S \\
S \\
S \\
T \\
S \\
S \\
S \\
S \\
T \\
T \\
S \\
S \\
T \\
S\end{array}$ \\
\hline $\begin{array}{l}21 \\
22 \\
23 * \\
24 \\
25 \\
26 \\
27\end{array}$ & $\begin{array}{l}50 \\
22 \\
55 \\
25 \\
54 \\
42 \\
42\end{array}$ & $\begin{array}{l}\text { Healthy } \\
\text { Healthy } \\
\text { Cardiac infarction } \\
\text { Healthy } \\
\text { Mitral stenosis } \\
\text { Mitral stenosis } \\
\text { Healthy }\end{array}$ & $\begin{array}{l}400 \\
400 \\
400 \\
422 \\
434 \\
434 \\
496\end{array}$ & $\begin{array}{c}\text { Over } \\
400\end{array}$ & $\begin{array}{l}200 \\
200 \\
200 \\
211 \\
217 \\
217 \\
248\end{array}$ & $\begin{array}{c}\text { Over } \\
200\end{array}$ & $\begin{array}{l}2: 1 \mathrm{~A}-\mathrm{V} \text { dissocia- } \\
\text { tion. Both auricular } \\
\text { waves within } \\
\text { ventricular waves }\end{array}$ & $\begin{array}{l}S \text { and } T \\
S \text { and } T \\
S \text { and } T \\
S \text { and } T \\
S \text { and } T \\
S \text { and } T \\
S \text { and } T\end{array}$ \\
\hline
\end{tabular}

* Denotes that the patient has since died.

$\uparrow$ The arrangement in four groups is based on the auricular rate and the degree of $\mathrm{A}-\mathrm{V}$ dissociation, both of which determine the conspicuity of the auricular waves in the cardiogram.

\section{Auricular Tachycardia of High Rate}

When the ventricular rate was 100 to 130 a minute and the auricular rate 200 to 260 , both auricular waves were visible outside the QRS and T waves, so that $2: 1 \mathrm{~A}-\mathrm{V}$ dissociation was obvious. Five of the 27 cases belong to this group (Cases 1 to 5; Fig. 3, 4, 5, and 6). The cardiogram in one case (Fig. 3) emphasizes how the clear portrayal of the auricular waves depends on the rate; thus in the $\mathrm{CR}_{1}$ lead both auricular waves were visible when the auricular rate was 210 a minute, but when the rate was 300 , one auricular wave became obscured within the $\mathrm{S}$ wave. The tracing from another patient (Fig. 7) similarly shows how the hidden auricular waves at high rate are unmasked when the A-V dissociation changes from $2: 1$ to $3: 1$ or $4: 1$. Three of the five patients had mitral stenosis, one was otherwise healthy and the other had hypertension and heart failure. . Two have since died and three survive. Quinidine produced no effect on the arrhythmia in two of the patients in whom it was tried; in another the rhythm changed to auricular fibrillation and later to normal rhythm during quini- 


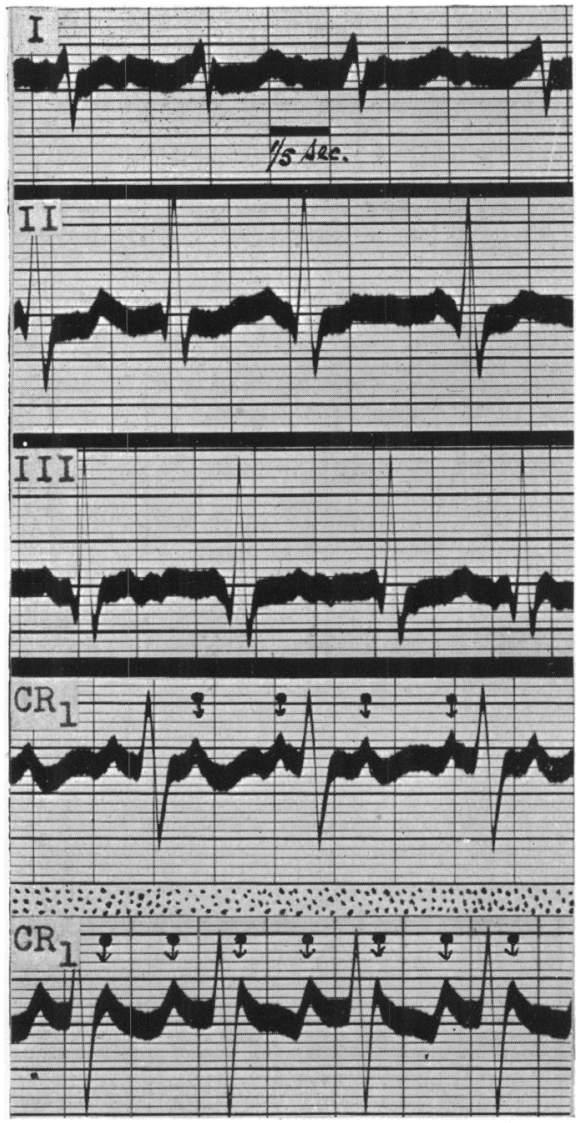

Fig. 3.-Auricular tachycardia with $2: 1 \mathrm{~A}-\mathrm{V}$ dissociation; A.R., 210. Both auricular waves outside ventricular waves. Second $\mathrm{CR}_{1}$ shows a more rapid rate (A.R., 300) so that one auricular wave is now obscured by $\mathbf{S}$ wave. Case 1 .

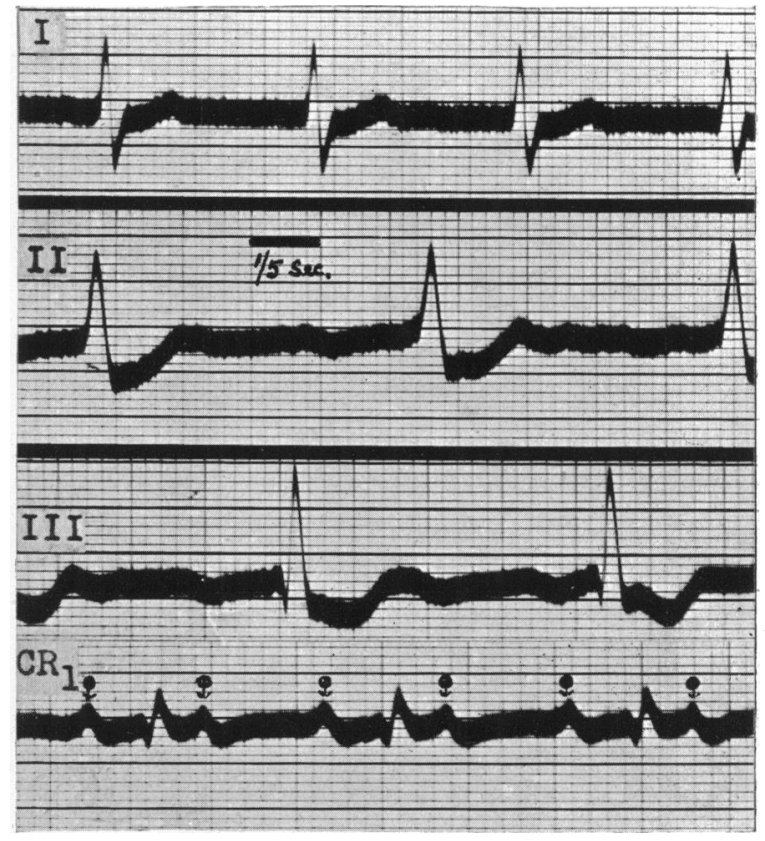

FIG. 4.-Auricular tachycardia with $2: 1$ A-V dissociation ; A.R., 212. Both auricular waves outside ventricular waves. Case 2.

dine therapy. In three patients digitalis changed the arrhythmia into auricular fibrillation which persisted in two during continued digitalization; in another, digitalis established normal rhythm directly.

\section{Auricular Tachycardia of Higher Rate}

When the ventricular rate was 130 to 200 a minute and the auricular rate was 260 to 400 , alternate auricular waves were hidden within the $S$ (in 11 cases) or $T$ waves (in 4 cases) of the ventricular complex, and the $2: 1 \mathrm{~A}-\mathrm{V}$ dissociation could not be made out in the limb lead tracing, but it was made apparent in the $\mathrm{CR}_{1}$ record. Fifteen of the 27 cases belong to this group (Cases 6 to 20; Fig. 7 to 14 and 21). When the auricular wave coincided with the $S$ it produced an upright extension of the $S$ in $C_{1}$ above the isoelectric level to form an $R^{1}$ wave, and whenever the same lead was recorded in normal rhythm this extra wave was absent. Manifestly this change is not the outcome of tachycardia alone, but is an expression of the presence of an auricular wave, because in rapid tachycardia of sinus origin (Fig. 2) the $R^{1}$ is not present. Six of the patients had mitral stenosis, three had hypertension, two had cardiac infarction, and four were healthy. Four have since died and eleven survive. Quinidine was not tried in 8 patients, but in 6 it had no effect, and in another it produced normal rhythm. Digitalis was not tried in 7 patients, but in 2 it had no effect, and in 6 it changed the rhythm into auricular fibrillation which in 2 reverted to normal rhythm. 


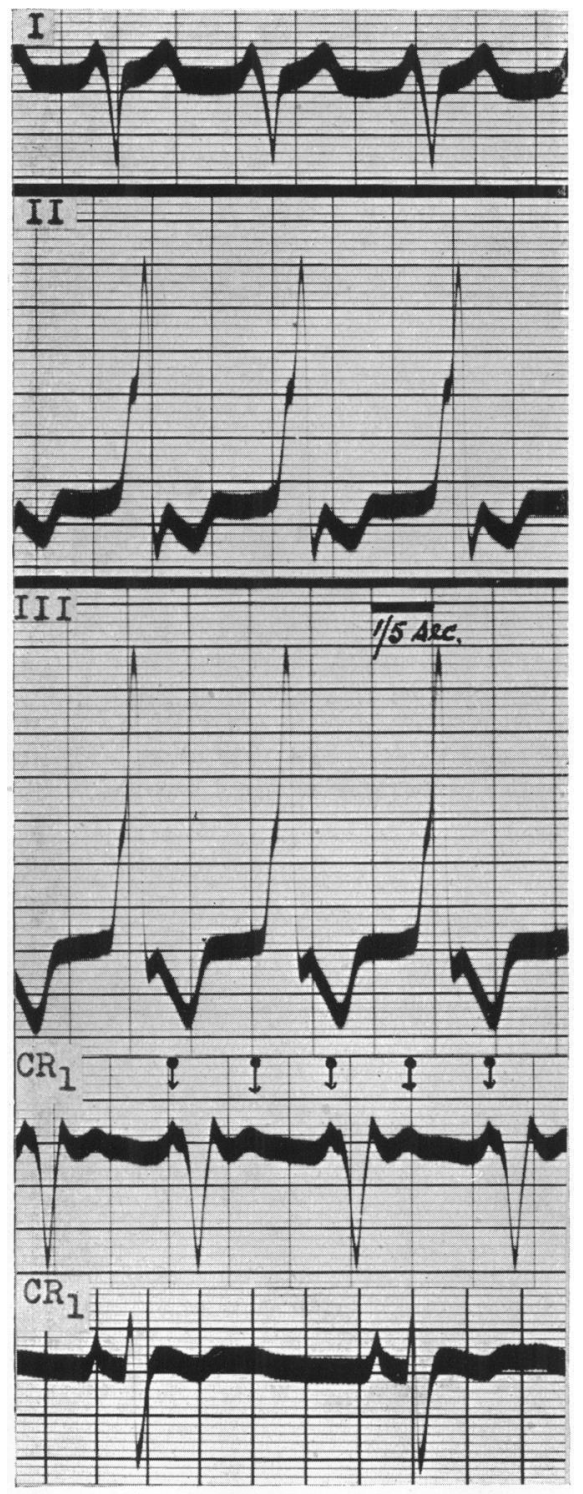

FIg. 5.-Auricular tachycardia with $2: 1$ A-V dissociation; A.R., 240. Both auricular waves outside ventricular waves. $\mathrm{CR}_{1}$ in normal rhythm for comparison showing inversion of $\mathrm{T}$ wave. Case 3.

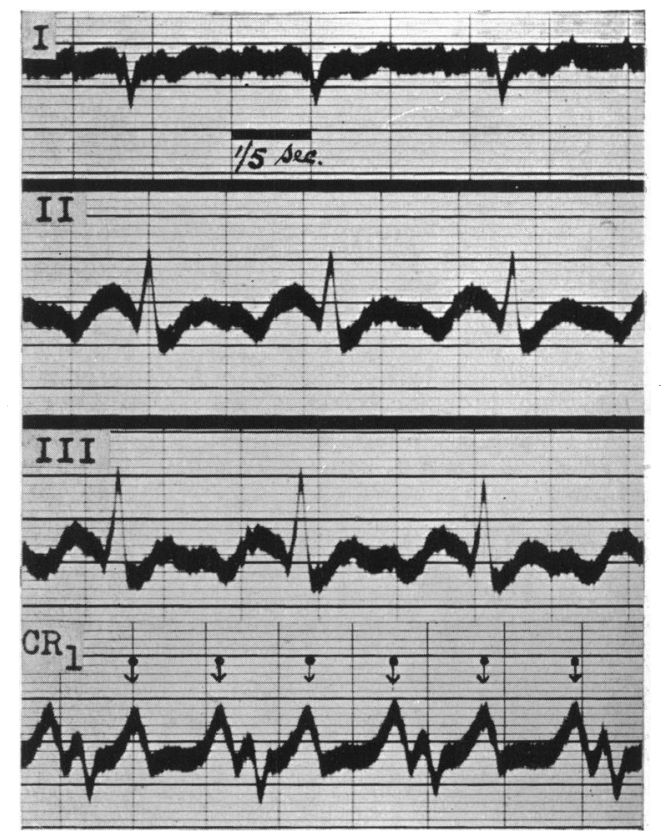

FIG. 6.-Auricular tachycardia with $2: 1$ A-V dis-. sociation; A.R., 256. Both auricular waves outside ventricular waves. Case 5.

\section{Auricular Tachycardia of Very High Rate}

When the ventricular rate was over 200 a minute and the auricular rate over 400 , both auricular waves were obscured within the $S$ and $T$ waves of the ventricular complex. Even at this high rate the auricular beats were demonstrated by a chest lead cardiogram, and best in $\mathrm{CR}_{1}$. Seven of the 27 cases belong to this group (Cases 21 to 27; Fig. 15 and 16). Two patients had mitral stenosis; another had cardiac infarction and died when the attack was three days old; four were otherwise healthy. Quinidine was not given to two patients, but in four it failed either to prevent or relieve the attacks; in another it succeeded. Digitalis also had no effect when tried in three of these patients, but it stopped the attack in one other. 

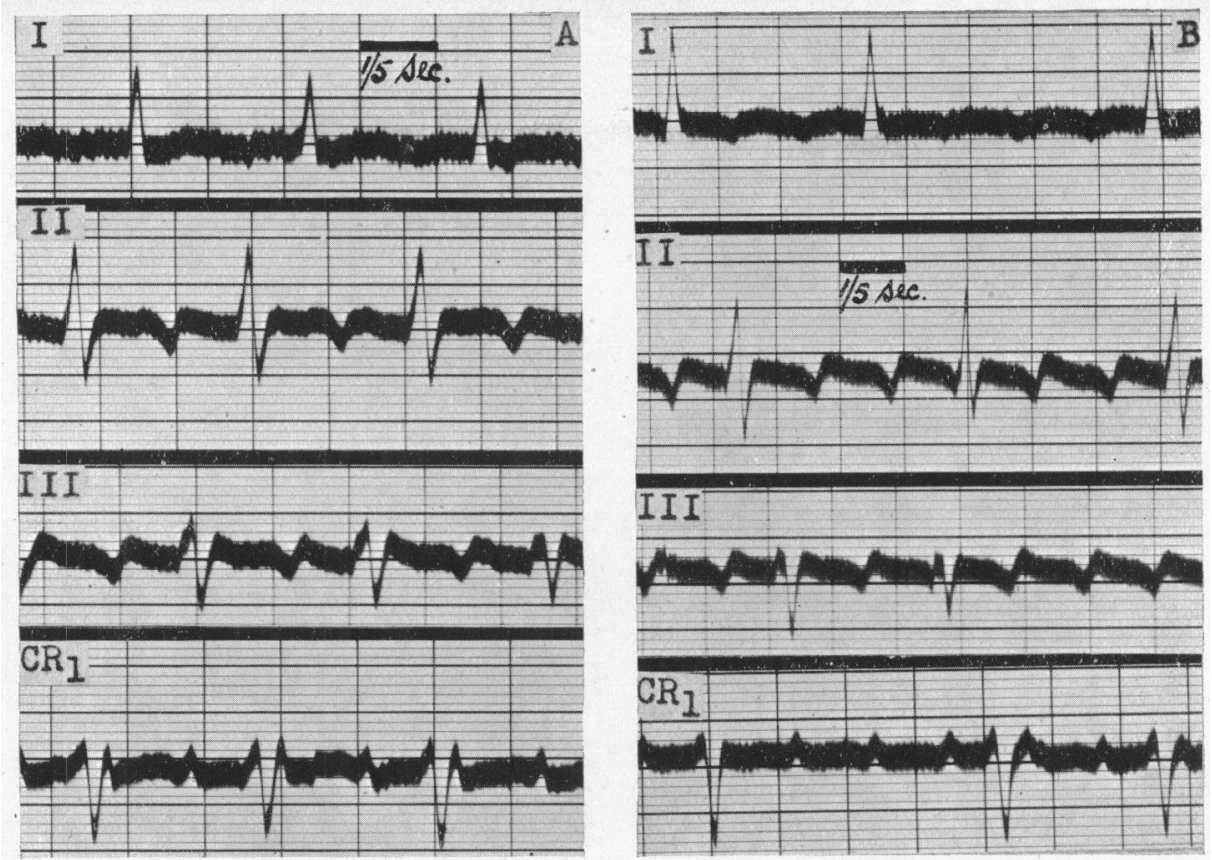

FIG. 7.-Auricular tachycardia with A-V dissociation. In (A) there is $2: 1$ dissociation and A.R. is 260, alternate auricular waves within S. Appearance of tracing suggests flutter. In (B) A.R. is still 260, but $\mathrm{A}-\mathrm{V}$ dissociation is $3: 1$ and $4: 1$ as a result of reduction in ventricular rate by digitalization. Tracings emphasize effect of ratio of $\mathrm{A}-\mathrm{V}$ dissociation in obscuring auricular waves in addition to effect of rate. Case 6.

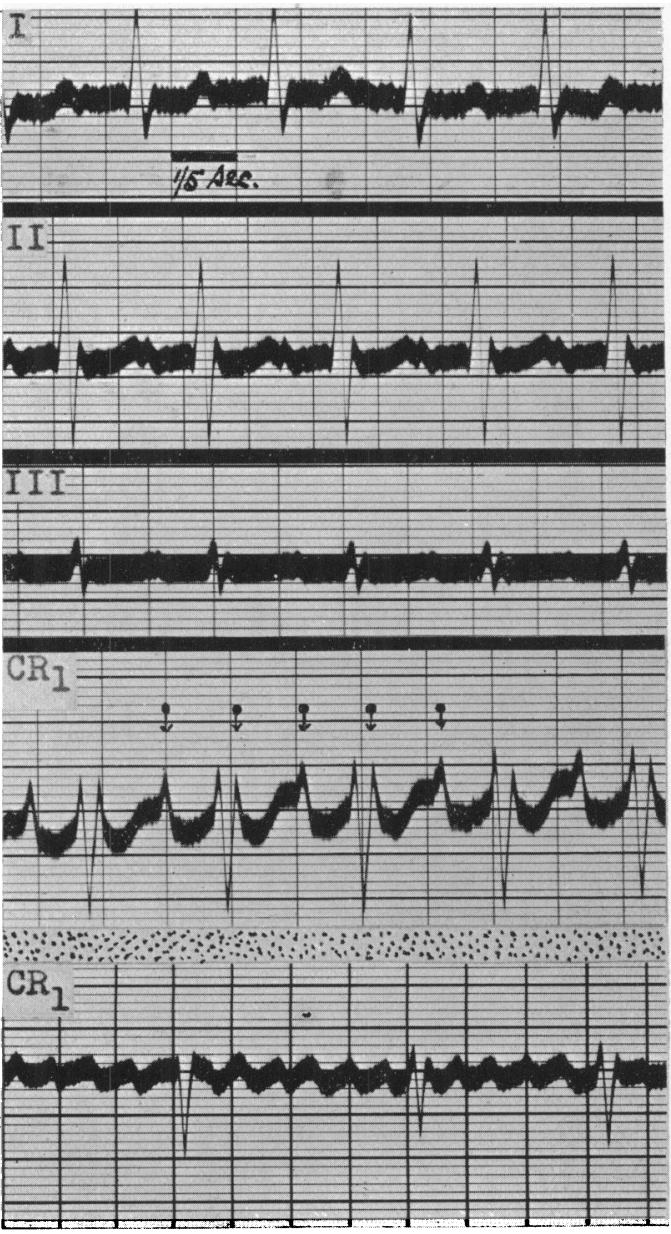

Fig. 8.-Auricular tachycardia with $2: 1$ A-V dissociation; A.R., 264. Alternate auricular waves within $\mathrm{S}$ wave producing an $\mathrm{R}^{1}$ wave. $\mathrm{CR}_{1}$ in auricular fibrillation for comparison showing disappearance of $R^{1}$. Case 7 .
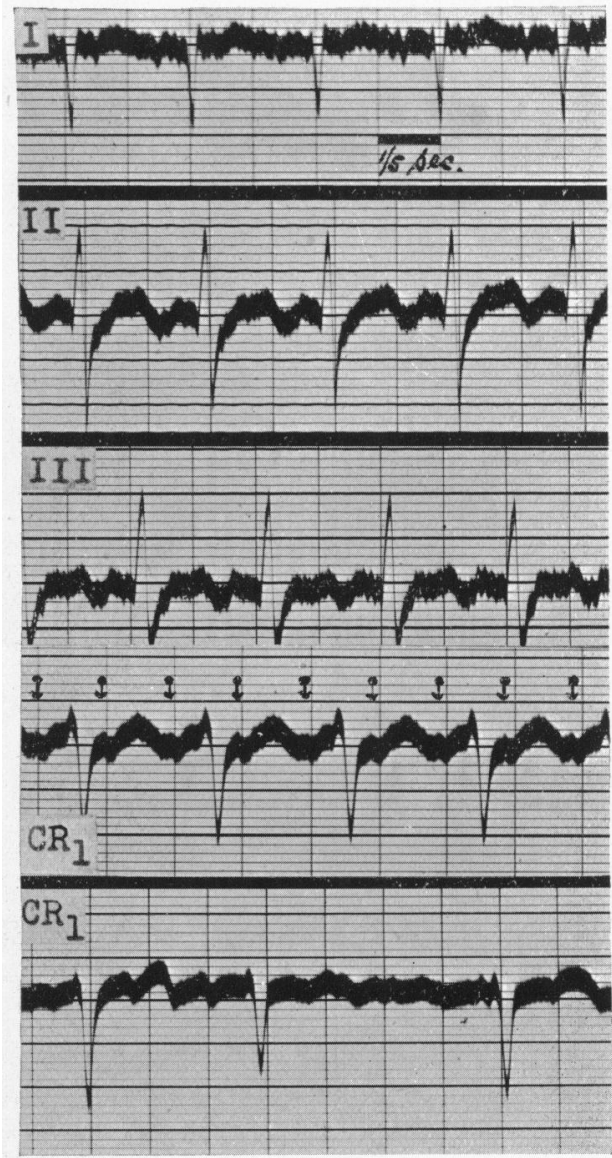

FIG. 9.-Auricular tachycardia with $2: 1$ A-V dissociation; A.R., 300. Alternate auricular waves within $\mathrm{S}$ wave. $\mathrm{CR}_{1}$ in auricular fibrillation for comparison. Case 12. 


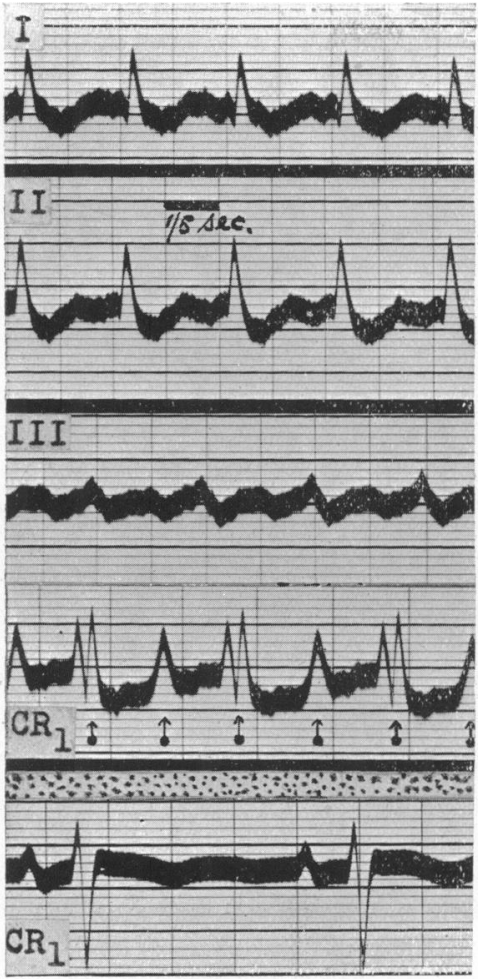

FIG. 10.-Auricular tachycardia with $2: 1$ A-V dissociation; A.R., 264. Alternate auricular waves within $S$ wave producing an $\mathrm{R}^{1}$ wave in $\mathrm{CR}_{1}$. $\mathrm{CR}_{1}$ in normal rhythm for comparison showing disappearance of $\mathbf{R}^{1}$ wave. Case 8 .
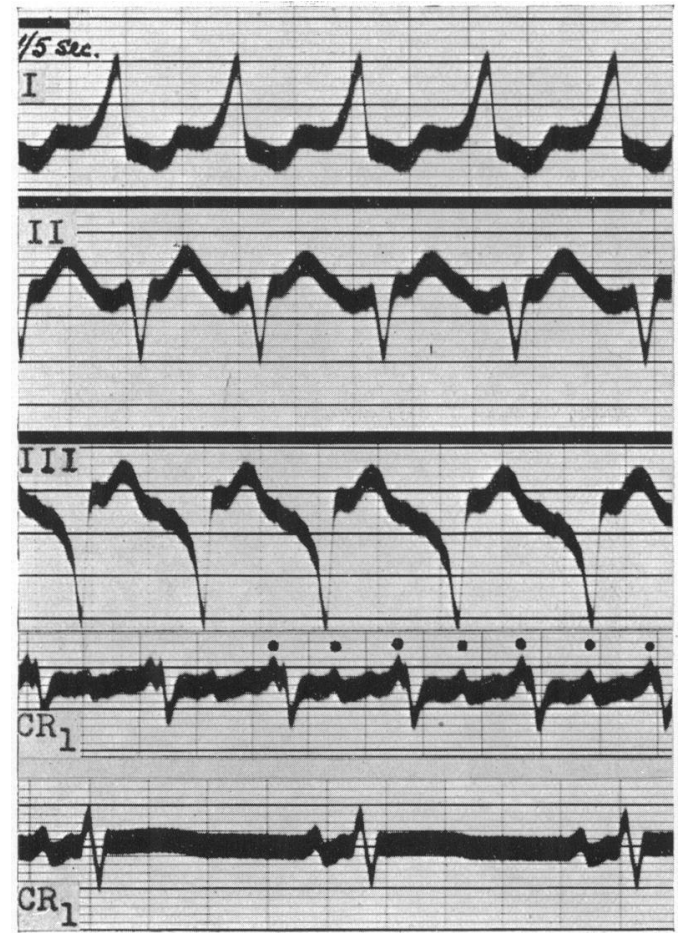

FIG. 12.-Auricular tachycardia with $2: 1 \mathrm{~A}-\mathrm{V}$ dissociation; A.R., 282. Alternate auricular waves within $\mathrm{T}$ wave. $\mathrm{CR}_{\mathbf{1}}$ in normal rhythm for comparison. Case 10.
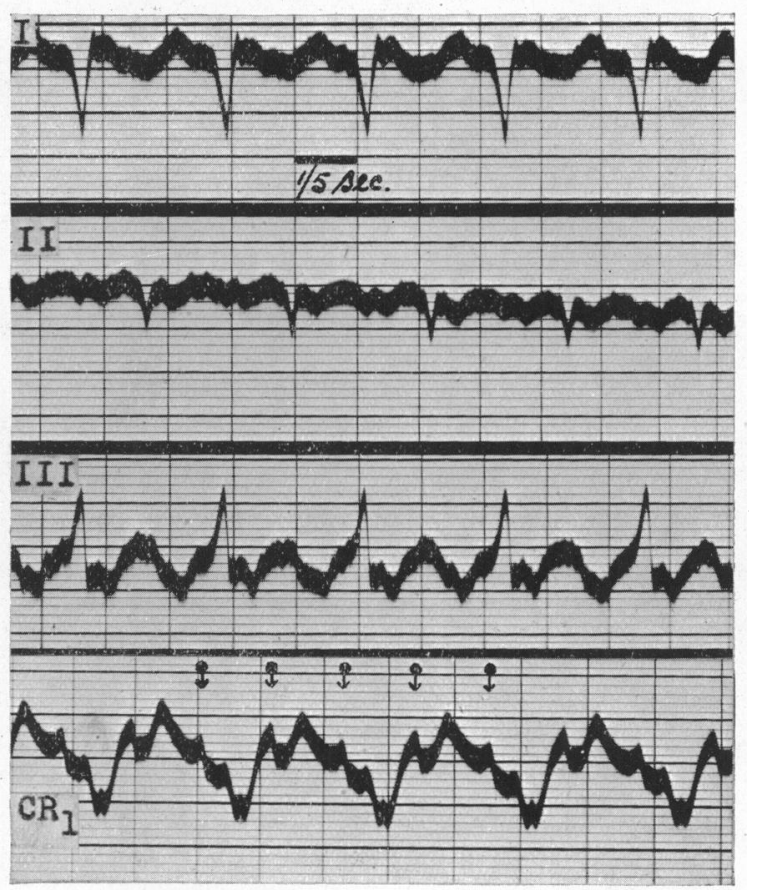

FIG. 11.-Auricular tachycardia with $2: 1$ A-V dissociation; A.R., 282. Alternate auricular waves within $\mathbf{S}$ wave producing an $R^{1}$ wave in $C_{1}$. Case 9.

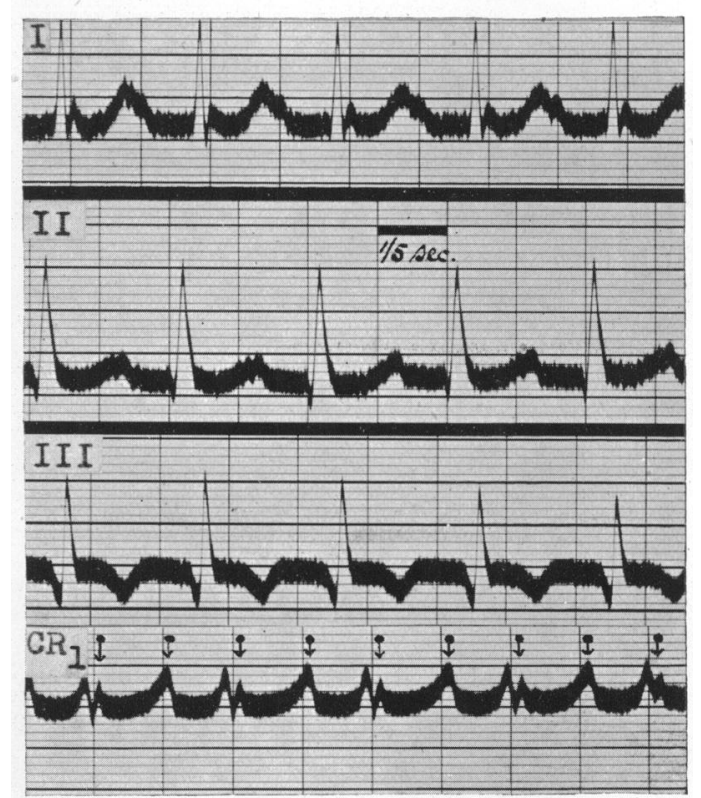

FIG. 13.-Auricular tachycardia with $2: 1 \mathrm{~A}-\mathrm{V}$ dissociation; A.R., 308. Alternate auricular waves within $S$ wave producing an $R^{1}$ wave in $C_{1}$. Case 13. 


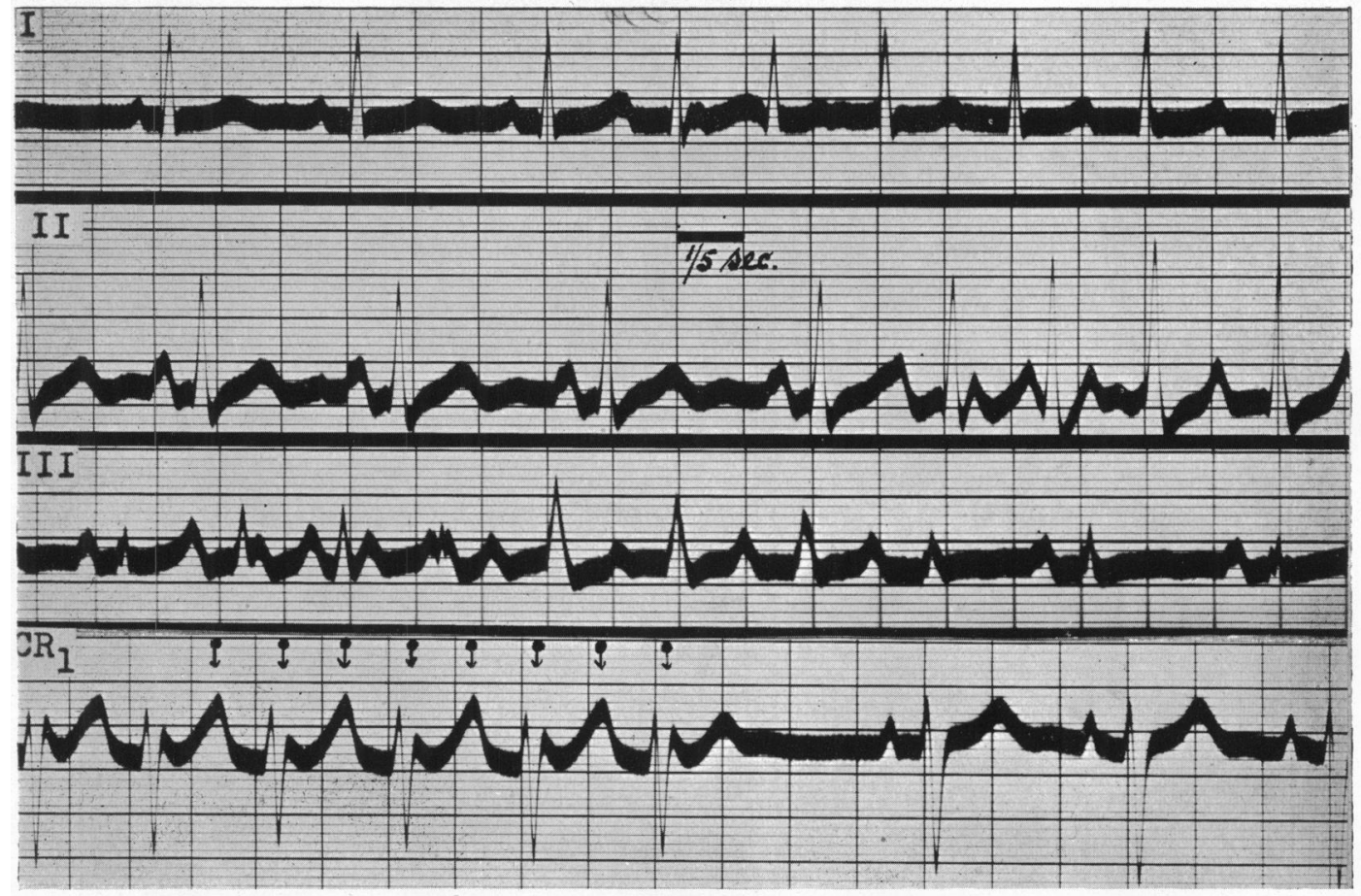

FIG. 14.- Short paroxysms of auricular tachycardia in each lead showing $2: 1 \mathrm{~A}-\mathrm{V}$ dissociation during such periods when auricular rate was 320 . An $R^{1}$ and a tall and peaky $T$ wave in $C_{1}$ produced by auricular waves, have disappeared during normal rhythm. Case 14.


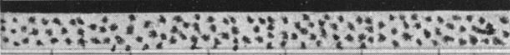
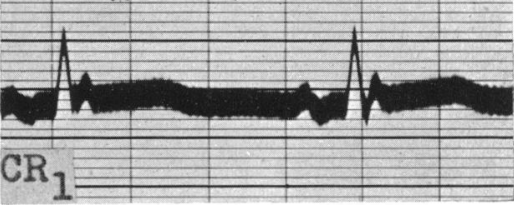

FIG. 15.-Auricular tachycardia with $2: 1 \mathrm{~A}-\mathrm{V}$ dissociation; A.R., 400. Auricular waves within $\mathrm{S}$ and $\mathrm{T}$ waves. Case 22.

Fig. 16.-Auricular tachycardia with $2: 1$ A-V dissociation; A.R., 496. Auricular waves within $\mathrm{S}$ and $\mathrm{T}$ waves. $\mathrm{CR}_{1}$ in normal rhythm for comparison. Case 27. 


\section{Auricular Tachycardia with Slow Ventricular Rate}

For comparison with the series of 27 cases of paroxysmal tachycardia, I have collected cases that had cardiograms showing a rapid and regular auricular action as an established arrhythmia but with a much slower ventricular rate (under 100 a minute). From among these, 7 have been listed in Table $I$ as being representative of a larger group. The auricular rate varied from 230 to 330 a minute and $\mathrm{A}-\mathrm{V}$ dissociation was present. The ventricular rate varied from 20 to 100 , and at least three consecutive auricular waves appeared outside the ventricular complexes. Rarely, the ventricular beats were regular and very slow because of complete heart block (Fig. 17). In other cases the ventricular beats were more frequent (Fig. 18 and 19) and occasionally occurring irregularly (Fig. 20). The auricular waves in II and III of the limb lead cardiogram from patients in this group conformed to the type customarily regarded as auricular flutter, and the intervals between the auricular waves in $\mathrm{CR}_{1}$ were at the isoelectric level.

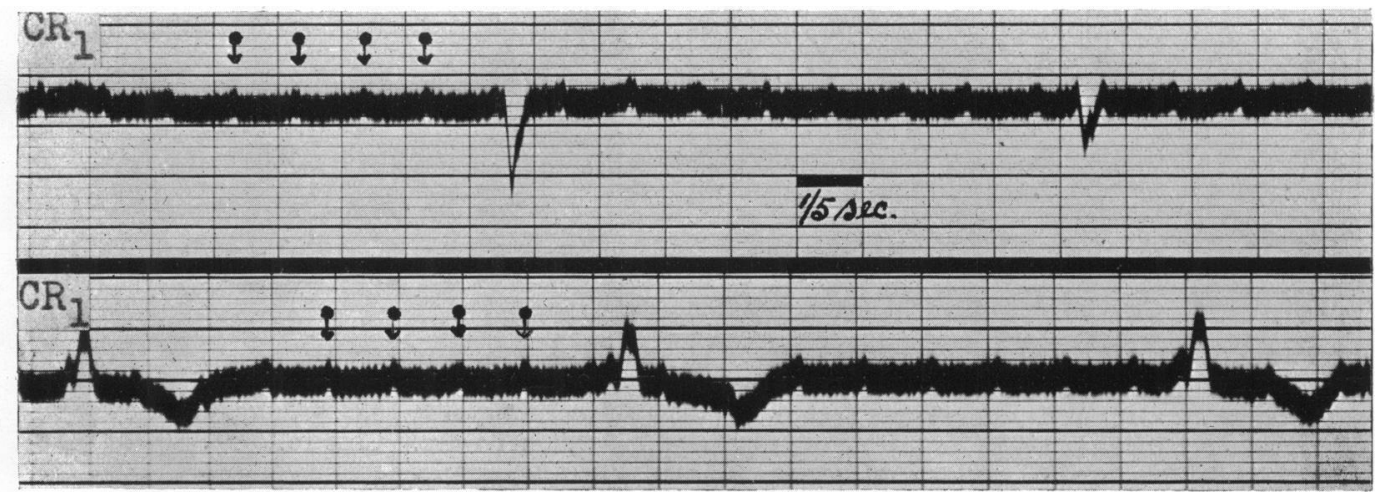

FIG. 17.-Auricular tachycardia with complete A-V dissociation; A.R., 280; V.R., 23. Several consecutive auricular waves appear outside ventricular complexes which in first $\mathrm{CR}_{1}$ are of right, and in second $\mathrm{CR}_{1}$ of left bundle branch block type. Female, aged 62, with hypertension.

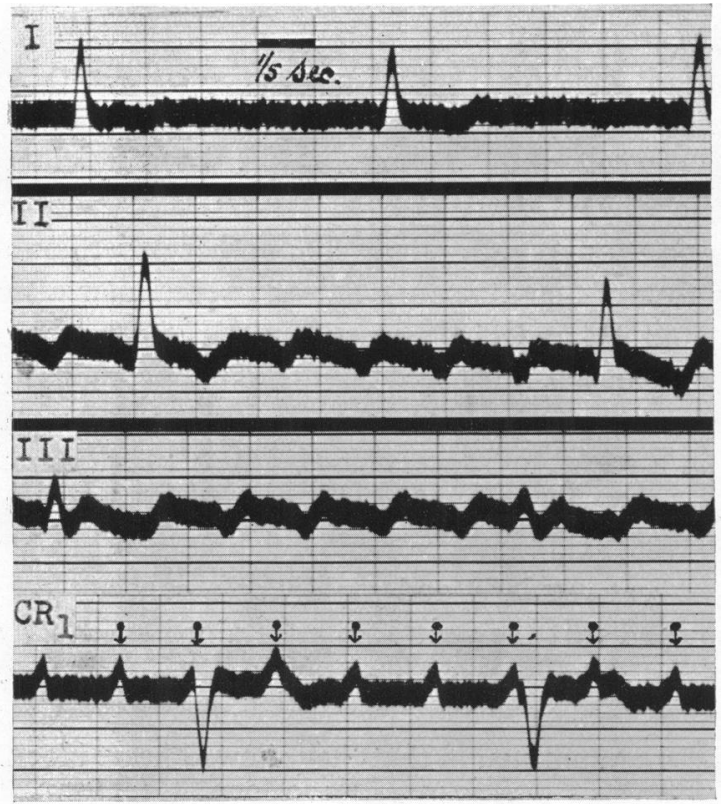

FIG. 18.-Auricular tachycardia with A-V dissociation; A.R., 230; V.R., 40 . Three or more consecutive auricular waves outside ventricular waves. Interauricular periods isoelectric in $\mathbf{C R}_{1}$. Male, aged 62, without heart disease.
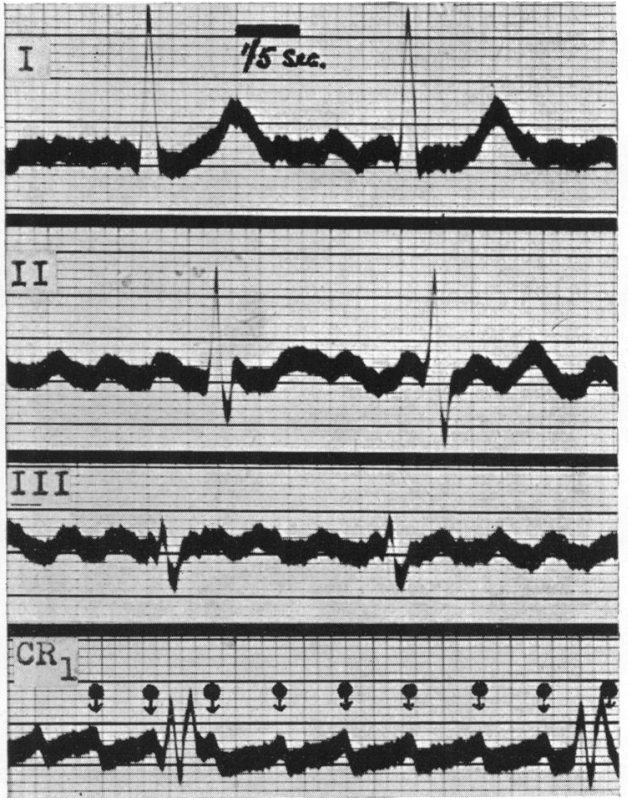

Fig. 19.-Auricular tachycardia with A-V dissociation; A.R., 328; V.R., 50. Three or more consecutive auricular waves outside ventricular waves. Male, aged 43 , with mitral stenosis. 


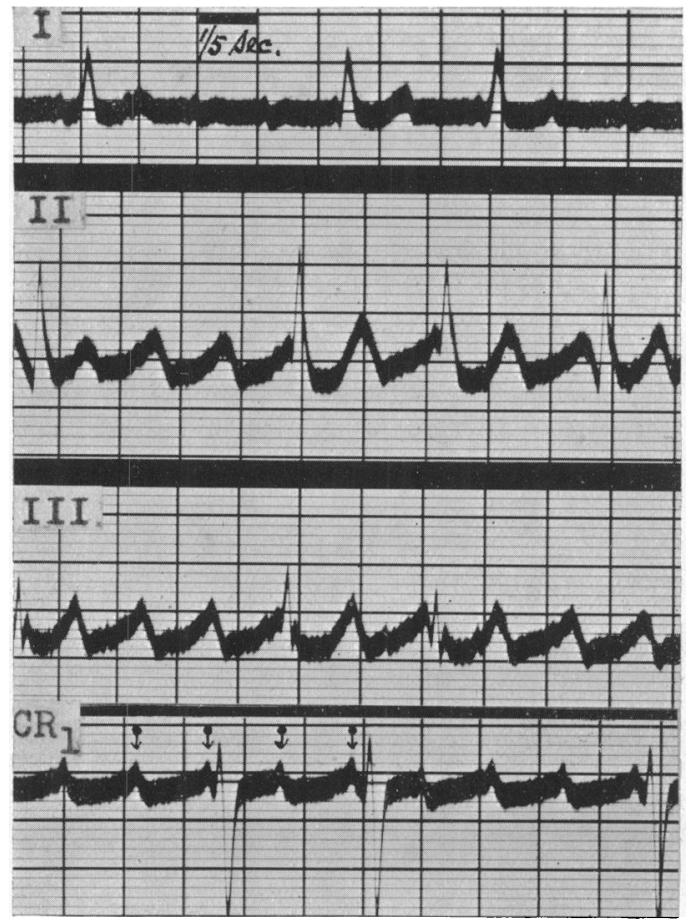

Fig. 20.-Auricular tachycardia with A-V dissociation; A.R., 236; V.R., 80. Three or more consecutive auricular waves outside ventricular waves. Male, aged 50, with mitral stenosis.
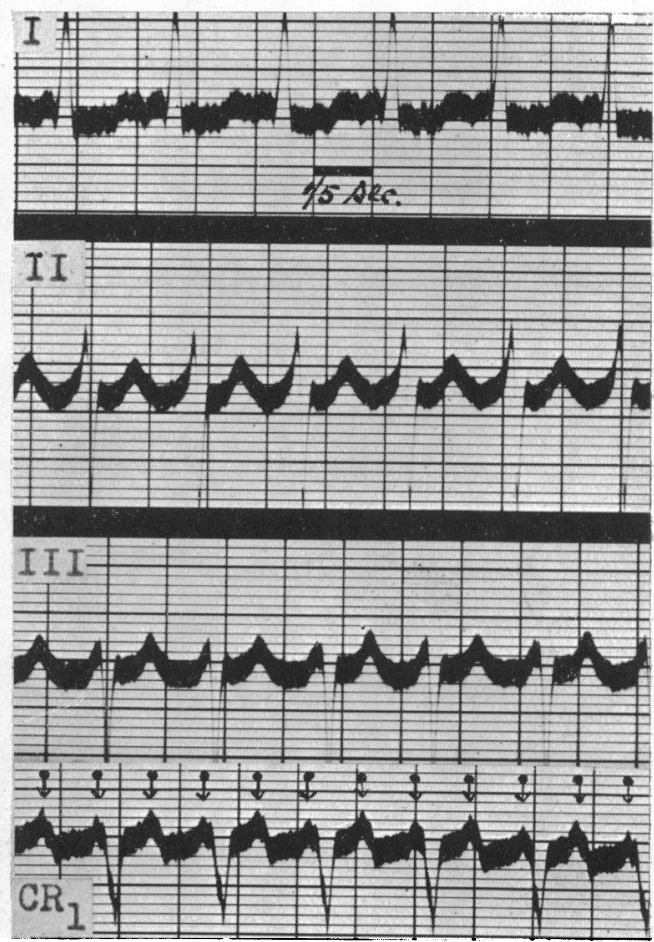

FIG. 21.-Auricular tachycardia with $2: 1$ A-V dissociation; A.R., 338: Alternate auricular waves within $\mathrm{T}$ wave. Case 16.

\section{A-V Dissociation in Paroxysmal Tachycardia}

Many instances of heart block have been reported in cases with paroxysmal tachycardia. Lewis $(1910 a)$ found that paroxysmal tachycardia frequently followed the ligation of a coronary artery in the experimental animal; it developed spontaneously whenever there was great acceleration of the ventricular rate. In 12 such instances heart block was noticed, but the auricular rate was half that of the fast ventricular rate. Later Lewis (1910b), recording simultaneous curves from auricle and ventricle by myocardiographic levers, alongside an electrocardiogram, demonstrated 2:1 A-V dissociation at high rates. In another paper Lewis (1912) described seven such cases in man; in four of them the auricular and ventricular rates were 300 and 150, 320 and 160, 224 and 112, and 334 and 167, respectively. In the first case the true interpretation of the cardiogram during tachycardia became possible by comparing it with later tracings recorded when the ventricular rate had been halved by digitalis therapy. The cardiogram of another case was shown in a paper by Mackenzie (1910) (his Fig. 56) as an example of paroxysmal tachycardia, but without reference to the $2: 1 \mathrm{~A}-\mathrm{V}$ dissociation which it demonstrated. Sprague and White (1925) said that the essential feature of auricular paroxysmal tachycardia, was that the auricles beat regularly and rapidly at a constant rate under the control of an abnormal pacemaker, and that the ventricles maintained an equally rapid rate, contracting in response to all the stimuli; there was no block between the chambers. They found, however, among 56 cases of paroxysmal tachycardia where electrocardiograms were recorded during attacks, 3 instances which were unusual in that they showed heart block. The auricular and ventricular rates in the three cases were 240 and 120, 220 and 110, and 190 and 95 , respectively. Single instances of heart block in paroxysmal tachycardia have been reported by Dock (1928), Laubry and Deglaude (1932), Carr (1932), Géraudel (1937), Maddox (1937), Fine and Miller (1940), Tanney and Lilienfeld (1942), and by Parsons (1943). 
An important contribution to the incidence of heart block in paroxysmal tachycardia was made by Brown (1936), who recorded an œsophageal electrogram, at the level of the left auricle, in two patients during the attack. Both showed $2: 1 \mathrm{~A}-\mathrm{V}$ dissociation. Brown said that his two cases provided evidence that A-V block does occur in auricular paroxysmal tachycardia, and that the auricular rate in this condition may rise certainly to 300 and very probably as high as 428 beats a minute. Barker, Wilson, Johnson, and Wishart (1943) reviewed 17 previously reported cases of auricular paroxysmal tachycardia associated with heart block, and described 18 cases of their own; 6 of their published cardiograms would be regarded by some as auricular flutter. They mentioned that in such cases the attacks often lasted longer than in the common type although they reported notable exceptions. The auricular rate was usually between 165 and 200 a minute, but much higher rates were also met with. They also noticed that patients of this group were often resistant to treatment. Speaking of cardiographic diagnosis they emphasized the difficulty of identifying the nature of the arrhythmia when the $\mathbf{P}$ waves were small or indistinct in the standard limb lead cardiogram. In such circumstances they mentioned that chest leads might prove helpful and they used it in 6 of their cases. A notable addition to the number of recorded cases of paroxysmal tachycardia with A-V block has been made by Decherd, Herrmann, and Schwab (1943), who described 40 patients showing this combined arrhythmia. It is not known whether some of their cases showed tracings that might be regarded as typifying auricular flutter because they. did not publish the three limb leads in any. Their experience led them to believe that the incidence of A-V block in paroxysmal tachycardia was much commoner than hitherto suspected. Death occurred in 22 cases (55 per cent) during their stay in hospital, and they concluded that the prognosis was serious in this group of patients; only 2 cases in the series were without heart disease, while 35 showed congestive heart failure even before the appearance of the arrhythmia. Decherd and his colleagues believed that the high incidence of heart disease and medication with quinidine or digitalis had contributed to the incidence of A-V block in their patients. The grade of block varied, but $2: 1$ was commonest and was recorded in 21 patients; it was $4: 3$ or $3: 2$ in 18 cardiograms which included three chest records.

\section{The' Relationship between Auricular Tachycardia and Auricular Flutter}

During paroxysmal tachycardia it is not possible on clinical grounds to tell whether the arrhythmia takes the form of auricular tachycardia or auricular flutter, although auricular flutter is favoured if the attack is prolonged. The difficulty of cardiographic interpretation when the rate is rapid is real. If $\mathrm{A}-\mathrm{V}$ dissociation became common to auricular tachycardia as well as to flutter, the pertinent question as to the difference between them would need an answer. The inclusion by Barker and his colleagues (1943) of 6 cardiograms that might be regarded by many as examples of auricular flutter, in a paper on paroxysmal tachycardia, provides another reason for examining the subject. Again, in their discussion of a paper on A-V dissociation in 40 cases of paroxysmal tachycardia Decherd et al. (1943) say that it must be explicitly stated that we do not possess absolute criteria for sharp differentiation between auricular tachycardia and flutter. Thus, the identification marks customarily applied to each in the past require to be examined again, and decision taken on their specificity for one type or their common application to both. The several characteristics of the two forms of arrhythmia will now be examined.

Historical. The term flutter was first used by MácWilliam (1887) when he wrote about the fibrillar contraction of the heart in the experimental animal. He stated that the phenomena resulting from faradic stimulation of the auricles differed in many respects from those witnessed in the ventricles. The application of the current set the auricles into a rapid flutter, the rapidity of which depended largely on the excitability of the auricular tissue and the strength of the current employed. He described the movements as regular and consisting of a series of 
contractions originating in the stimulated area and thence spreading over the rest of the tissue. The movement showed no sign of incoordination, and it looked like a rapid series of contraction waves spreading over the auricular walls. MacWilliam did not tell of the ventricular response to such movements, neither did he record them instrumentally, but only interpreted his visual impression. When Jolly and Ritchie (1910) reported a case of rapid and regular action of the auricle ( 250 to 300 a minute) they applied the term auricular flutter to the electrocardiogram because it seemed to represent the phenomenon observed and described by MacWilliam during experimental auricular tachycardia. After that the term came into common use.

Duration of the Attack. Auricular flutter, although not uncommonly presenting as brief paroxysms, is more often met with as an established condition. Parkinson and Bedford (1927) stated that flutter in paroxysms constituted a special variety of paroxysmal tachycardia. In about 25 per cent of cases, flutter was purely paroxysmal and was then frequently associated with paroxysms of fibrillation. Auricular tachycardia, on the other hand, although sometimes maintained for long periods, is usually confined to brief attacks. In addition to finding exceptions in each group, I found this distinction between the two kinds of arrhythmia to be fairly closely related to the rate. Thus, cases that show the relatively longer paroxysms of tachycardia have a less rapid auricular rate (300 or less a minute) and often a ratio of A-V dissociation greater than $2: 1$.

The Auricular Rate. A high auricular rate (about 300 a minute) has been regarded as characteristic of auricular flutter, serving to distinguish it from auricular paroxysmal tachycardia with its slower rate of about 160 to 240 a minute. But now that $\mathrm{A}-\mathrm{V}$ dissociation has been shown to occur in auricular tachycardia, and to be an invariable feature of it in the cases reported here, the high auricular rate may prove to be common to both arrhythmia, at least in most cases. Further, the auricular rate in auricular tachycardia is quite stable as in flutter and is not often altered appreciably by rest, posture, emotion, or exercise.

Response to Treatment. Pressure on the carotid sinus in patients in this series never had the effect of slowing either auricular or ventricular rate sufficiently to separate the auricular and ventricular complexes in the cardiogram. Only once did this manœuvre stop an attack, in a patient in whom the paroxysms were very brief. Parkinson and Nicholl (1922) tried quinidine in six cases of paroxysmal tachycardia, in two of which the attacks were prolonged; in none were they satisfied that quinidine had a beneficial effect. Barker, Wilson, and Johnston (1943) stated that quinidine slowed the heart rate in paroxysmal tachycardia as it did the cireus movement in flutter. Quinidine was tried in 15 of the 27 cases; in 12 it had no effect; in one it produced auricular fibrillation; in two it restored normal rhythm. In none did quinidine prevent the return of the attacks. The conversion of paroxysmal tachycardia into auricular fibrillation by digitalis has been reported by Lewis (1912), and by Barker, Wilson, Johnston, and Wishart (1943). Digitalis was tried in 16 of my cases; in 6 it had no effect; in 7 it changed the rhythm into auricular fibrillation, and later normal rhythm was resumed in 3 of these; in 3 digitalis restored normal rhythm directly. Such effects are also witnessed in the treatment of auricular flutter with quinidine and digitalis. Quinidine, or quinidine and digitalis alternately, was tried by Parkinson and Bedford (1927) in the treatment of 27 cases of auricular flutter. They found that digitalis removed flutter far more often than did quinidine. Digitalis alone restored normal rhythm in over a third of the cases, and in another third it induced fibrillation. Quinidine converted flutter directly into normal rhythm in about one case in five; it often cut short paroxysms of flutter, though continued small doses did not entirely prevent their recurrence. Where digitalis had left fibrillation, quinidine sometimes converted this into normal rhythm. Bourne (1933) reported a return to normal rhythm in two out of three cases of paroxysmal tachycardia during digitalization. Campbell and Suzman (1934) observed a case of auricular flutter and rheumatic heart disease for six years; while the patient was taking 
the same dose of digitalis as had been dispensed over two years, normal rhythm was restored, but only for three months. In another case of auricular flutter without heart disease, Lewis (1937) watched the arrhythmia continue, without impairment of the heart's efficiency for 24 years; digitalization had proved of no avail.

$A-V$ Dissociation. Hitherto A-V dissociation has been regarded as typical of auricular flutter and a rare happening in paroxysmal tachycardia, but this distinction can no longer apply now that it has been found in so many instances of auricular tachycardia; 17 cases by various authors; 16 by Barker et al. (1943); 40 by Decherd et al. (1943); and in every case in this series of 27.

Presence of Heart Disease. Out of 100 cases of paroxysmal tachycardia reported by Campbell and Elliott (1939) 55 were healthy. Among 52 cases of auricular flutter examined by Parkinson and Bedford (1927) there were only 5 without heart disease. Another 7 such cases were reported by Orgain, Wolff, and White (1936). Among my 27 cases of paroxysmal tachycardia, there were 11 with mitral stenosis, 4 with hypertension, 3 with cardiac infarction, and 9 who were healthy.

Mechanism. When Mines (1913) described circus rhythm he suggested that it might be responsible for some cases of paroxysmal tachycardia. From their observations on the effects of quinidine upon paroxysms, Iliescu and Sebastiani (1923) believed that auricular tachycardia was due to circus contraction. Lewis (1925) pointed out that the total amount of auricular muscle was not sufficiently large to accommodate a circus mechanism at known rates of conduction in auricular muscle and with cycles as long as those which occur in auricular paroxysmal tachycardia. Now that a more rapid auricular rate has been found common in auricular tachycardia, a circus mechanism cannot be excluded on that ground. This problem has been studied again by Barker, Wilson, and Johnston (1943), and they found strong evidence that auricular paroxysmal tachycardia is caused by circus rhythm involving one of the specialized nodes, either the sino-auricular or auriculo-ventricular node.

Interchangeability of Rhythm. It is known (Lewis, 1912; Parkinson and Matthias, 1915; and Carr, 1932) that paroxysmal auricular tachycardia may change spontaneously to auricular flutter or fibrillation, and flutter or fibrillation may change to paroxysmal tachycardia. This suggests that the conditions are related one to another.

Auricular Deflections and Interauricular Period. In every case in this series the auricular wave was upright in the right pectoral lead suggesting that the ectopic impulse had its origin near the sino-auricular node. It has been held that the auricular movements depicted in the cardiogram of auricular flutter are continuous and that the record does not show any pauses at the isoelectric level between the beats. This is usually true for the limb leads II and III, but it is not true for œsophageal and certain chest leads. Thus in cases that showed such continuous auricular waves in leads II and III, there were usually quiescent intervals between auricular waves at the isoelectric level in the $\mathbf{C R}_{1}$ cardiogram (Fig. 17, 18, and 20). Similar silent pauses were present in all the other examples of auricular tachycardia. The high auricular and ventricular rate in auricular tachycardia has made the cardiographic diagnosis of auricular flutter less frequent, for the ventricular waves have obscured the pattern of the auricular waves in the limb leads. This is well illustrated in a case of paroxysmal auricular tachycardia reported by Parkinson and Matthias (1915). In their Fig. 4 a sudden infrequency of the ventricular beats has unmasked four consecutive auricular beats which appear typical of those customarily regarded as auricular flutter; the auricular rate of 240 a minute continued as in the earlier part of the record. The same unmasking of auricular beats by a slower ventricular rate is illustrated in Fig. 7 of the present paper. Barker, Wilson, and Johnston (1943) have pointed out that complete separation of the auricular deflections by isoelectric periods is consistent with the continuation of activity during circus movement, provided the circus path traverses either the sino-auricular or auriculo-ventricular node. These authors have postulated that such circumstances operate in paroxysmal auricular tachycardia. 


\section{DisCUSSION}

There has been no lack of research into paroxysmal tachycardia; indeed the medical literature over a period of 30 years records many observations on the behaviour of the human heart during the attack and under the influence of treatment intended to abort the attack. But the outcome of past research has not been to agree on the nature and mechanism of this rapid heart action. The reproduction of a comparable state in the experimental animal has been difficult so that little help has come from that source. Clinically the description of the attacks has been accepted from patients examined in the intervals between the attacks and in the absence of cardiographic observations during a paroxysm of tachycardia. Gradually, the similarity of paroxysmal tachycardia and auricular flutter has been noticed clinically and cardiographically, and since it has now been shown that A-V dissociation is a common feature of paroxysmal tachycardia as well as of flutter, the common design of the two forms of arrhythmia appears more real. Should this uniformity receive emphasis by the results of further investigation, it will simplify the clinical and cardiographic diagnosis, and allow attention to be directed to a trial of digitalis and quinidine for aborting the attack, and otherwise to consider prognosis and additional treatment in relation to the presence and nature of the underlying heart disease.

If the presence of A-V dissociation in paroxysmal tachycardia, found in every patient in this series, is confirmed by future cardiographic investigation, the terms paroxysmal tachycardia and auricular flutter will have become interchangeable.

Thus, auricular flutter is paroxysmal tachycardia in which a moderate auricular rate (200 to 260) facilitates the finding of A-V dissociation in the cardiogram, because both auricular waves are separate from the two main waves of the ventricular complex; a greater A-V dissociation from slowing of the ventricular rate shows three or more consecutive auricular waves outside the ventricular complex even at higher auricular rates.

Again, paroxysmal tachycardia is auricular flutter where the more rapid auricular rate (260 to 500) prejudices the recognition of the auricular waves hidden within the ventricular complexes and hinders the discovery of a 2:1 A-V dissociation. In such circumstance comparison of a right pectoral cardiogram in an attack with one in normal rhythm will help in deciphering the nature of the arrhythmia.

From the clinical standpoint the attacks in the first group are inclined to be longer, more amenable to digitalis influence, and more certain to be associated with heart disease. But to each of these three distinctive features there are common exceptions.

\section{CONCLUSION}

A right pectoral electrocardiogram $\left(\mathrm{CR}_{1}\right)$ demonstrated the presence of $\mathrm{A}-\mathrm{V}$ dissociation, usually $2: 1$, in 27 consecutive cases of paroxysmal tachycardia. Further investigation is necessary before assigning this feature to all or to the majority of such patients.

In the meantime the finding suggests the common unity of paroxysmal tachycardia and auricular flutter, with auricular tachycardia as the essential mechanism of each, showing variations in rate and in the degree of $\mathrm{A}-\mathrm{V}$ dissociation.

I wish to thank Dr. John Parkinson, Physician to the Cardiac Department, for his helpful criticism of this paper. Mr. William Dicks, Technician to the Department, has collaborated in producing most of the cardiograms.

\section{Abstract of Case Notes}

Case 1. A man, aged 47, with mitral stenosis. Complained of shortness of breath and attacks of palpitation. Systolic and mid-diastolic murmurs in mitral area. No clinical evidence of heart failure. Cardioscopy showed moderate enlargement of heart from mitral stenosis, and slight pulmonary congestion. Electrocardiogram (EC.) shown in Fig. 3.

Quinidine failed to prevent or abort attacks. Digitalis converted arrhythmia into auricular fibrillation. 
Case 2. A woman, aged 60, with mitral stenosis. Complained of shortness of breath and palpitation. Clinical evidence of mitral stenosis with much cardiac enlargement, and failure. Cardioscopy showed aneurysmal dilatation of left auricle and pulmonary congestion.

When attack of tachycardia persisted (Fig. 4), digitalis converted it into auricular fibrillation. Quinidine was never tried.

Case 3. An otherwise healthy man, aged 21. Complained of palpitation for over three years. Latterly attacks had lasted for some months. No abnormal signs on clinical or cardioscopic examination. EC. shown in Fig. 5.

Digitalis restored normal rhythm in four days. Quinidine was not tried.

Case 4. A man, aged 69, with hypertensive heart failure. Admitted to hospital because of nocturnal breathlessness. Blood pressure 170/110. Triple rhythm from addition of fourth heart sound, and other signs of left ventricular failure. Diffuse chronic bronchiectasis. Developed bronchopneumonia and tachycardia. EC. showed auricular tachycardia with $2: 1 \mathrm{~A}-\mathrm{V}$ dissociation; A.R., 254 ; both auricular waves outside ventricular waves.

Quinidine changed rhythm to auricular fibrillation and to normal rhythm. Further attacks of tachycardia uninfluenced by quinidine or digitalis, and patient died.

Case 5. A woman, aged 28. Attacks of tachycardia and symptoms of heart failure over some years. Presystolic murmur of mitral stenosis. Cardioscopy showed moderate cardiac enlargement, and pulmonary congestion. EC. shown in Fig. 6.

On one occasion arrhythmia converted into auricular fibrillation by digitalis therapy, but later neither digitalis nor quinidine prevented or relieved attacks. Death took place from heart failure and pulmonary infarction.

Case 6. A man, aged 68, with hypertensive heart failure. Increasing breathlessness for five months. Severe nocturnal dyspnœa for three months. Four attacks of palpitation in last ten days; last attack had been persisting for four days. Great cardiac enlargement and pulmonary congestion from hypertension. EC. shown in Fig. 7.

Quinidine for ten days had no effect on abnormal rhythm, but digitalis over same period slowed ventricular rate and established normal rhythm seven days later.

Case 7. A woman, aged 58, with mitral stenosis and hypertension. Dyspnœa for a year and attacks of tachycardia for a month. Blood pressure 220/115. Clinical signs of mitral stenosis. Cardioscopy showed moderate cardiac enlargement, and pulmonary congestion. EC. shown in Fig. 8.

Digitalis on one occasion changed rhythm to auricular fibrillation. Quinidine was never prescribed. Death came suddenly from pulmonary infarction.

Case 8. A woman, aged 65. Attacks of palpitation for 3 years. Systolic and mid-diastolic murmurs of mitral stenosis. Cardioscopy showed moderate enlargement of heart. EC. shown in Fig. 10.

Quinidine restored normal rhythm on one occasion, and digitalis converted it into auricular fibrillation another time.

Case 9. A woman, aged 53. Sudden onset of tachycardia eight days before. Clinical diagnosis obscured by tachycardia, but cardioscopy showed great enlargement of heart from mitral stenosis. EC. shown in Fig. 11.

Quinidine for 7 days had no effect, but digitalis converted it into auricular fibrillation.

Case 10. A man, aged 52. Frequent attacks of palpitation lasting an hour or a day at a time for eight years. Presystolic murmur of mitral stenosis. Cardioscopy showed moderate enlargement of heart, and slight pulmonary congestion. EC. shown in Fig. 12.

Neither quinidine nor digitalis prevented or aborted attacks.

Case 11. A woman, aged 63, with hypertensive heart failure. Symptoms and signs of left ventricular failure for some months with recent onset of attacks of paroxysmal tachycardia. Cardioscopy showed enlargement of left ventricle, and pulmonary congestion. EC. showed auricular tachycardia with $2: 1$ A-V dissociation; A.R., 292; alternate auricular waves within $\mathrm{S}$ wave.

Digitalis and quinidine had no effect on attacks.

Case 12. A man, aged 58, with mitral stenosis. Frequent short attacks of palpitation over many months. EC. shown in Fig. 9.

Quinidine was never given. Digitalis on one occasion changed rhythm to auricular fibrillation and thence to normal rhythm.

Case 13. An otherwise healthy woman, aged 38. Brief attacks of palpitation. No abnormal clinical findings in between attacks. EC. shown in Fig. 13.

Neither quinidine nor digitalis prevented or relieved attacks.

Case 14. An otherwise healthy woman, aged 34. Complained of attacks of palpitation, lasting a few minutes or hours, for 18 months. No abnormal signs on clinical examination which included cardioscopy. EC. shown in Fig. 14.

Neither quinidine nor digitalis was tested for relief or prevention of attacks. 
Case 15. A woman, aged 61. Recent onset of heart failure from hypertension, and attacks of palpitation. EC. showed auricular tachycardia with $2: 1$ A-V dissociation; A.R., 332 ; alternate auricular waves within $T$ wave.

Patient died soon after admission into hospital and before quinidine or digitalis could be tried.

Case 16. A man, aged 50. Symptoms of heart failure from mitral stenosis and aortic incompetence for one year with recent onset of attacks of palpitation. EC. shown in Fig. 21.

Patient died in hospital before effects of digitalis or quinidine could be observed.

Case 17. An otherwise healthy woman, aged 64. Complained of frequent attacks of tachycardia lasting for hours at a time and over a period of twelve years. No abnormal signs on clinical examination nor on cardioscopy. EC. showed auricular tachycardia with 2:1 A-V dissociation; A.R., 342; alternate auricular waves within $\mathbf{S}$ wave.

Neither digitalis nor quinidine proved effective as prophylactic measure.

Case 18. A man, aged 53. Recent cardiac infarction with fall of blood pressure to 90/70. Developed rapid heart action, and EC. showed auricular tachycardia with $2: 1 \mathrm{~A}-\mathrm{V}$ dissociation; A.R., 364; alternate auricular waves within S wave. Inversion of T in leads II and III during normal rhythm, disappearing in subsequent tracings, was regarded as effect of tachycardia, but inversion of $T$ I persisted as evidence of cardiac infarction.

Quinidine had no effect on tachycardia, but digitalis changed it into auricular fibrillation before converting it into normal rhythm.

Case 19. A man, aged 59, with hypertensive heart failure. Developed cardiac infarction and rapid heart action. EC. showed auricular tachycardia with $2: 1$ A-V dissociation; A.R., 376; alternate auricular waves within $\mathrm{T}$ wave.

Patient died before effects of digitalis or quinidine could be tested.

Case 20. An otherwise healthy woman, aged 19. Recurrent attacks of palpitation. No evidence of heart disease on clinical examination nor on cardioscopy. EC. showed auricular tachycardia with $2: 1 \mathrm{~A}-\mathrm{V}$ dissociation; A.R., 380; alternate auricular waves within $\mathrm{S}$ wave.

Attack aborted before quinidine or digitalis could be tried.

Case 21. An otherwise healthy woman, aged 50. Periodic attacks of palpitation for 16 years. No evidence of cardiovascular disease on clinical examination nor on cardioscopy. EC. showed auricular tachycardia with 2:1 A-V dissociation; A.R., 400; both auricular waves obscured by $\mathrm{S}$ and $\mathrm{T}$ waves.

Digitalis and quinidine ineffective in relieving or preventing attacks.

Case 22. An otherwise healthy man, aged 22. Four attacks of rapid heart action within six years. Attacks more frequent for three months. On clinical examination and cardioscopy no abnormal signs. EC. shown in Fig. 15.

Digitalis appeared to shorten one attack, and quinidine another.

Case 23. A man, aged 55, with tachycardia three weeks after cardiac infarction. EC. showed auricular tachycardia with 2:1 A-V dissociation; A.R., 400; both auricular waves obscured by $\mathrm{S}$ and $\mathrm{T}$ waves.

Attack persisted until death, 8 days later. Quinidine failed to change rhythm. Digitalis was not tried.

Case 24. An otherwise healthy man, aged 25. Periodic attacks of palpitation. Clinical and radiological examination showed no cardiovascular disease. EC. showed auricular tachycardia with 2 : 1 A-V dissociation; A.R., 422; both auricular waves obscured by $S$ and $T$ waves.

Neither quinidine nor digitalis was tried.

Case 25. A man, aged 54. Periodic attacks of palpitation over 20 years. Clinical and radiological evidence of mitral stenosis and aortic incompetence. EC. during attack showed auricular tachycardia with $2: 1 \mathrm{~A}-\mathrm{V}$ dissociation; A.R., 434; both auricular waves obscured by $\mathrm{S}$ and $\mathrm{T}$ waves.

Neither quinidine nor digitalis proved beneficial in preventing or relieving attacks.

Case 26. A woman, aged 42. Attacks of palpitation for two years. Cardioscopy showed moderate enlargement of heart from mitral stenosis, but there was no evidence of failure. EC. during an attack showed auricular tachycardia; auricular rate was 434 a minute one time and 218 another time, but with $2: 1 \mathrm{~A}-\mathrm{V}$ dissociation on both occasions.

Digitalis and quinidine were not tried.

Case 27. An otherwise healthy man, aged 42. Attacks of tachycardia, lasting upwards of 6 hours, for 5 years. Neither clinical nor radiological examination showed any cardiovascular disease. EC. shown in Fig. 16.

Both quinidine and digitalis failed to prevent or relieve attacks.

\section{REFERENCES}

Barker, P. S., Wilson, F. N., Johnston, F. D., and Wishart, S. W. (1943). Amer. Heart J., $25,765$. Barker, P. S., Wilson, F. N., and Johnston, F. D. (1943). Ibid., 26, 435.

Bourne, G. (1933). Lancet, 1, 686. 
Brown, W. H. (1936). Amer. Heart J., 12, 307.

Campbell, M., and Elliott, G. A. (1939). Brit. Heart J., 1, 123.

Campbell, M., and Suzman, S. S. (1934). Lancet, 2, 923.

Carr, F. B. (1932). Amer. Heart J., 7, 668.

Decherd, G. M., Herrmann, G. R., and Schwab, E. H. (1943). I Ibid., 26, 446.

Dock, W. (1928). Arch. intern. Med., 41, 745.

Evans, W. (1941). Brit. Heart J., 3, 247.

Fine, M. J., and Miller, R. (1940). Amer. Heart J., 20, 366.

Géraudel, E. (1937). Arch. Mal. Cour, 30, 796.

Iliescu, C. C., and Sebastiani, A. (1923). Heart, 10, 223.

Jolly, W. A., and Ritchie, W. T. (1910). Ibid., 2, 177.

Laubry, C., and Deglaude, L. (1932). Arch. Mal. Caur, 25, 28.

Lewis, T. (1910a). Heart, 1, 98.

(1910b). Ibid., 1, 306.

(1912). Ibid., 3, 279.

(1925). The Mechanism and Graphic Registration of the Heart Beat. Third ed., London.

(1937). Brit. med. J., 1, 1248.

Mackenzie, J. (1910). Heart, $2,273$.

MacWilliam, J. A. (1887). J. Physiol., 8, 296.

Maddox, K. (1937). Amer. Heart J., 14, 183.

Mines, G. R. (1913). J. Physiol., 46, 349.

Orgain, E. S., Wolff, L., and White, P. D. (1936). Arch. intern. Med., 57, 493.

Parkinson, J., and Bedford, D. E. (1927). Quar. J. Med., 21, 21.

Parkinson, J., and Matthias, H. H. (1915). Heart, 6, 27.

Parkinson, J., and Nicholl, J. W. McK. (1922). Lancet, 2, 1267.

Parsons, C. G. (1943). Brit. Heart J., 5, 187.

Sprague, H. B., and White, P. D. (1925). Med. Clin. North Amer., 8, 1855.

Tanney, A. D., and Lilienfeld, A. (1942). Ann. intern. Med., 16, 616. 